\section{Ocular complications with high-dose interferon alpha in chronic active hepatitis}

Abstract

Purpose Interferon alpha, which is used to treat various systemic disorders, has many reversible side-effects involving various organ systems. In this study, chronic active hepatitis patients undergoing interferon alpha therapy were followed with regard to the ocular sideeffects.

Methods Thirty-six patients with chronic active hepatitis undergoing subcutaneous interferon alpha therapy for 1 year were enrolled. Complete ocular examination and photographic documentation were performed at baseline of the therapy and monthly thereafter. Fisher's exact chi-squared test and Mann-Whitney $U$-test were employed in the statistical evaluation of the results.

Results Trichomegaly was noted in $2(6 \%)$ patients. Fifteen patients $(42 \%)$ were found to have retinopathy with cotton wool spot formation and splinter haemorrhages. Conclusions These findings emphasise the need to monitor these retinal complications, which may result in loss of vision in patients receiving interferon alpha therapy.

Key words Hepatitis, Interferon alpha, Retinopathy, Trichomegaly

Recombinant interferon alpha (IFN $\alpha$ ) has been used in the treatment of various systemic disorders due to its capacity to create an antiviral effect, to inhibit cell proliferation and to modulate immunity. ${ }^{1,2}$ Therapy with IFN $\alpha$ is frequently associated with mild to moderate systemic effects including a 'flu-like syndrome with fatigue, fever, anorexia, nausea and diarrhoea; neutropenia and thrombocytopenia; cardiovascular and central nervous system events, such as chest pain, cardiomyopathy, arrhythmia, numbness and dizziness; and increased liver function enzyme levels, proteinuria, autoimmune disorders such as thyroiditis and polyarthropathy, rash, dryness of the skin and oropharynx, pruritis, alopecia, weight loss and depression. ${ }^{3,4}$ Though uncommon, ocular side-effects that may result in loss of vision have been reported. ${ }^{5}$
In this study, we report the ocular follow-up of patients with chronic viral hepatitis undergoing IFN $\alpha$ therapy.

\section{Patients and methods}

Thirty-six consecutive patients, in whom IFN $\alpha$ therapy for chronic active viral hepatitis was started between January and June 1996, were included in the study. There were 25 males and 11 females. The mean age of the patients was 38.6 years (range 18-66 years). Hepatitis $C$ virus (HCV) RNA was positive in 20 and hepatitis B virus surface antigen was positive in 16 patients. Nineteen patients, 1 of whom, was a type 2 diabetic, had chronic renal failure necessitating regular haemodialysis, 1 other patient had type 2 diabetes mellitus and 6 patients had controlled hypertension only (Table 1).

Recombinant IFN $\alpha 2 b$ (Intron A, ScheringPlough, Kenilworth, NJ) was administered subcutaneously (6 million international units (MIU) in hepatitis C, and 10 MIU in hepatitis B) three times per week for 12 months.

All patients underwent a complete ocular examination before IFN $\alpha$ therapy consisting of visual acuity measurement (Snellen chart), slitlamp examination, applanation tonometry, and direct and indirect ophthalmoscopy after full pupillary dilatation. Fundus photographs were taken and recorded digitally using the Digital Imaging System (Topcon IMAGEnet-640, Paramus, NJ). Examinations were repeated monthly, except in cases with retinopathy, where more frequent follow-up was employed. After the cessation of therapy at the end of 12 months, the patients were examined every 3 months for a further year. Gonioscopy, perimetry, colour vision, examination for relative afferent pupillary defect and fluorescein angiography were performed when indicated.

Twelve other patients with chronic active viral hepatitis who were not receiving IFN $\alpha$ therapy were also examined and followed up for 2 years at 3-month intervals. The mean age of these patients was 43.4 years (range 16-70

\author{
S. Kadayifcilar \\ P. Aydin \\ Department of \\ Ophthalmology \\ Başkent University School \\ of Medicine \\ Ankara, Turkey \\ S. Boyacioglu \\ H. Kart \\ M. Gursoy \\ Department of \\ Gastroenterology \\ Başkent University School \\ of Medicine \\ Ankara, Turkey \\ Pinar Aydin, \\ MD. Ph.D \\ Başkent University School \\ of Medicine \\ Department of \\ Ophthalmology \\ 10. Sokak 06490 Bahçelievler \\ Ankara, Turkey \\ Tel: +90 3122150349 \\ Fax: +90 2132237333 \\ Part of this work was \\ presented at the \\ XIth Congress of the \\ European Society of \\ Ophthalmology, 1997
}

Received: 10 July 1998 Accepted in revised form: 9 December 1998 
Table 1. Clinical characteristics of the patients receiving IFNa

\begin{tabular}{|c|c|c|c|c|c|c|c|c|c|c|}
\hline $\begin{array}{l}\text { Patient } \\
\text { no. }\end{array}$ & $\begin{array}{c}\text { Age } \\
\text { (years) }\end{array}$ & Sex & CRF & $\mathrm{DM}$ & $\begin{array}{c}\text { IFN } \alpha \text { dose } \\
(\mathrm{MIU} \times 3 / \text { week })\end{array}$ & Retinopathy & Time $^{a}$ & Htc & Plt & OOC \\
\hline 1 & 24 & M & - & - & 10 & - & & $\mathrm{N}$ & $\downarrow$ & \\
\hline 2 & 25 & F & - & - & 10 & - & & $\downarrow$ & $\mathrm{N}$ & \\
\hline 3 & 34 & $M$ & - & - & 10 & - & & $\mathrm{N}$ & $\downarrow$ & \\
\hline 4 & 34 & $\mathrm{M}$ & - & - & 10 & + & 4 & $\mathrm{~N}$ & $\mathrm{~N}$ & \\
\hline 5 & 40 & $\mathrm{M}$ & - & - & 10 & + & 5 & $\downarrow$ & $\downarrow$ & \\
\hline 6 & 53 & $\mathrm{M}$ & - & - & 10 & - & & $\downarrow$ & $\downarrow$ & \\
\hline 7 & 49 & M & - & - & 10 & - & & $\mathrm{N}$ & $\downarrow$ & \\
\hline 8 & 44 & $\mathrm{M}$ & - & - & 10 & + & 3 & $\mathrm{~N}$ & $\downarrow$ & \\
\hline 9 & 66 & $\mathrm{~F}$ & - & - & 10 & + & 4 & $\mathrm{~N}$ & $\downarrow$ & \\
\hline 10 & 22 & $\mathrm{M}$ & + & - & 10 & + & 2 & $\mathrm{~N}$ & $\mathrm{~N}$ & $\operatorname{Tr}$ \\
\hline 11 & 39 & $\mathrm{M}$ & - & - & 10 & + & 2 & $\mathrm{~N}$ & $\mathrm{~N}$ & \\
\hline 12 & 48 & $\mathrm{M}$ & - & - & 10 & - & & $\mathrm{N}$ & $\mathrm{N}$ & \\
\hline 13 & 24 & $\mathrm{~F}$ & + & - & 10 & + & 2 & $\downarrow$ & $\mathrm{N}$ & \\
\hline 14 & 44 & F & + & - & 10 & - & & $\downarrow$ & $\mathrm{N}$ & \\
\hline 15 & 46 & $\mathrm{M}$ & - & - & 10 & - & & $\mathrm{N}$ & $\mathrm{N}$ & \\
\hline 16 & 28 & $\mathrm{M}$ & + & - & 10 & + & 2 & $\downarrow$ & $\mathrm{N}$ & \\
\hline 17 & 44 & $\mathrm{~F}$ & + & - & 6 & + & 4 & $\downarrow$ & $\mathrm{N}$ & \\
\hline 18 & 61 & M & - & - & 6 & - & & $\mathrm{N}$ & $\mathrm{N}$ & \\
\hline 19 & 19 & F & + & - & 6 & - & & $\downarrow$ & $\mathrm{N}$ & \\
\hline 20 & 52 & $\mathrm{M}$ & - & - & 6 & - & & $\mathrm{N}$ & $\mathrm{N}$ & PC \\
\hline 21 & 49 & $\mathrm{~F}$ & - & - & 6 & + & 3 & $\mathrm{~N}$ & $\downarrow$ & \\
\hline 22 & 43 & $\mathrm{M}$ & + & - & 6 & + & 1 & $\downarrow$ & $\mathrm{N}$ & \\
\hline 23 & 42 & $\mathrm{M}$ & + & - & 6 & + & 1 & $\downarrow$ & $\mathrm{N}$ & $\operatorname{Tr}$ \\
\hline 24 & 28 & $\mathrm{M}$ & + & - & 6 & - & & $\downarrow$ & $\mathrm{N}$ & \\
\hline 25 & 60 & $\mathrm{M}$ & + & - & 6 & + & 3 & $\mathrm{~N}$ & $\downarrow$ & \\
\hline 26 & 29 & $\mathrm{M}$ & + & - & 6 & - & & $\mathrm{N}$ & $\mathrm{N}$ & \\
\hline 27 & 60 & M & - & + & 6 & - & & $\downarrow$ & $\mathrm{N}$ & \\
\hline 28 & 14 & $\mathrm{M}$ & + & - & 6 & - & & $\downarrow$ & $\mathrm{N}$ & \\
\hline 29 & 20 & $\mathrm{M}$ & + & - & 6 & - & & $\mathrm{N}$ & $\mathrm{N}$ & \\
\hline 30 & 35 & F & + & - & 6 & - & & $\downarrow$ & $\mathrm{N}$ & \\
\hline 31 & 47 & $\mathrm{M}$ & + & - & 6 & - & & $\mathrm{N}$ & $\mathrm{N}$ & \\
\hline 32 & 37 & $\mathrm{M}$ & + & - & 6 & - & & $\downarrow$ & $\downarrow$ & \\
\hline 33 & 32 & $\mathrm{M}$ & + & - & 6 & - & & $\downarrow$ & $\mathrm{N}$ & \\
\hline 34 & 36 & $\mathrm{~F}$ & + & - & 6 & - & & $\downarrow$ & $\downarrow$ & \\
\hline 35 & 59 & $\mathrm{~F}$ & + & + & 6 & + & 2 & $\downarrow$ & $\mathrm{N}$ & \\
\hline 36 & 39 & $\mathrm{~F}$ & + & - & 6 & + & 1 & $\downarrow$ & $\downarrow$ & HRVO \\
\hline
\end{tabular}

CRF, chronic renal failure; DM, diabetes mellitus; Htc, haematocrit; Plt, platelet count; N, normal; $\downarrow$, reduced ( $<41 \%$ for Htc in males, $<37 \%$ for Htc in females, $<140000 / \mathrm{mm}^{3}$ for Plt); OOC, other ocular complications; $\mathrm{Tr}$, trichomegaly; $\mathrm{HRVO}$, hemicentral retinal vein occlusion; PC, preseptal cellulitis.

${ }^{a}$ Time after duration of therapy at which therapy was first detected; months unless otherwise specified.

years). There were 7 males and 5 females. Chronic renal failure was present in 5 patients and type 2 diabetes mellitus in 1.

Each patient had measurement of vital signs and physical examination at baseline and at follow-up examinations. Haematological evaluations were conducted before enrolment and then weekly for the first month and monthly thereafter.

In the statistical evaluation of the results, Fisher's exact chi-squared test and Mann-Whitney $U$-test were employed.

\section{Results}

At the baseline examination none of the patients complained of ophthalmic symptoms, and no retinal lesions, except myopic chorioretinal degeneration in one case (no. 28, Tables 1,2), were found. The visual acuity data are presented in Table 2. The blood pressure of the patients with chronic renal failure was under control, but 3 of those in the IFN $\alpha$ group had grade I-II hypertensive retinopathy.
During the study period, preseptal cellulitis developed in 1 patient (no. 20, Table 1), and his laboratory investigation revealed leucopenia. In 2 cases (nos. 10 and 23, Table 1) an increase in the length of the eyelashes was noted after the sixth month of therapy (Fig. 1).

Retinopathy characterised by cotton wool spots and/or tiny superficial haemorrhages was detected in 19 eyes of 15 patients. These changes were noted early in the course of therapy, most within the first 2 months (Table 1). Cotton wool spots were commonly seen posterior to the equator, outside the major temporal vascular arcades. Intraretinal haemorrhages were nearly always associated with the cotton wool spots.

Consecutive examinations 1-2 weeks apart revealed that the cotton wool spots disappeared completely in 5 patients, decreased in number in 4 , and resolved but appeared at another location in 4 patients. Retinopathy progressed in 2 patients (nos. 4 and 23, Table 1) to involve the papillomacular bundle. In one of these (no. 23), high-resolution perimetry revealed a suspicious defect in the upper nasal quadrant. A relative afferent 


\begin{tabular}{|c|c|c|c|c|c|c|c|c|}
\hline \multirow[b]{2}{*}{ Patient no. } & \multirow[b]{2}{*}{$\mathrm{IFN} \alpha$} & \multirow[b]{2}{*}{ Retinopathy } & \multicolumn{2}{|c|}{ First VA } & \multicolumn{2}{|c|}{ Second VA } & \multicolumn{2}{|c|}{ Third VA } \\
\hline & & & OD & OS & OD & OS & OD & OS \\
\hline 1 & + & - & $20 / 20$ & $20 / 20$ & $20 / 20$ & $20 / 20$ & $20 / 20$ & $20 / 20$ \\
\hline 2 & + & - & $20 / 20$ & $20 / 20$ & $20 / 20$ & $20 / 20$ & $20 / 20$ & $20 / 20$ \\
\hline 3 & + & - & $20 / 20$ & $20 / 20$ & $20 / 20$ & $20 / 20$ & $20 / 20$ & $20 / 20$ \\
\hline 4 & + & + & $20 / 20$ & $20 / 20$ & $20 / 20$ & $20 / 20$ & $20 / 20$ & $20 / 20$ \\
\hline 5 & + & + & $20 / 20$ & $20 / 20$ & $20 / 20$ & $20 / 20$ & $20 / 20$ & $20 / 20$ \\
\hline 6 & + & - & $20 / 25$ & $20 / 20$ & $20 / 20$ & $20 / 20$ & $20 / 20$ & $20 / 20$ \\
\hline 7 & + & - & $20 / 25$ & $20 / 25$ & $20 / 25$ & $20 / 25$ & $20 / 25$ & $20 / 25$ \\
\hline 8 & + & + & $20 / 20$ & $20 / 20$ & $20 / 20$ & $20 / 20$ & $20 / 20$ & $20 / 20$ \\
\hline 9 & + & + & $20 / 20$ & $20 / 20$ & $20 / 20$ & $20 / 20$ & $20 / 20$ & $20 / 20$ \\
\hline 10 & + & + & $20 / 20$ & $20 / 20$ & $20 / 20$ & $20 / 20$ & $20 / 20$ & $20 / 20$ \\
\hline 11 & + & + & $20 / 20$ & $20 / 20$ & $20 / 20$ & $20 / 20$ & $20 / 20$ & $20 / 20$ \\
\hline 12 & + & - & $20 / 20$ & $20 / 20$ & $20 / 20$ & $20 / 20$ & $20 / 20$ & $20 / 20$ \\
\hline 13 & + & + & $20 / 20$ & $20 / 20$ & $20 / 20$ & $20 / 20$ & $20 / 20$ & $20 / 20$ \\
\hline 14 & + & - & $20 / 20$ & $20 / 20$ & $20 / 20$ & $20 / 20$ & $20 / 20$ & $20 / 20$ \\
\hline 15 & + & - & $20 / 20$ & $20 / 20$ & $20 / 20$ & $20 / 20$ & $20 / 20$ & $20 / 20$ \\
\hline 16 & + & + & $20 / 20$ & $20 / 20$ & $20 / 20$ & $20 / 20$ & $20 / 20$ & $20 / 20$ \\
\hline 17 & + & + & $20 / 20$ & $20 / 20$ & $20 / 20$ & $20 / 20$ & $20 / 20$ & $20 / 20$ \\
\hline 18 & + & - & $20 / 20$ & $20 / 20$ & $20 / 20$ & $20 / 20$ & $20 / 20$ & $20 / 20$ \\
\hline 19 & + & - & $20 / 20$ & $20 / 20$ & $20 / 25$ & $20 / 25$ & $20 / 25$ & $20 / 25$ \\
\hline 20 & + & - & $20 / 20$ & $20 / 20$ & $20 / 20$ & $20 / 20$ & $20 / 20$ & $20 / 20$ \\
\hline 21 & + & + & $20 / 20$ & $20 / 20$ & $20 / 20$ & $20 / 20$ & $20 / 20$ & $20 / 20$ \\
\hline 22 & + & + & $20 / 20$ & $20 / 20$ & $20 / 20$ & $20 / 20$ & $20 / 20$ & $20 / 20$ \\
\hline 23 & + & + & $20 / 20$ & $20 / 20$ & $20 / 20$ & $20 / 20$ & $20 / 20$ & $20 / 20$ \\
\hline 24 & + & - & $20 / 20$ & $20 / 20$ & $20 / 20$ & $20 / 20$ & $20 / 20$ & $20 / 20$ \\
\hline 25 & + & + & $20 / 20$ & $20 / 20$ & $20 / 20$ & $20 / 20$ & $20 / 20$ & $20 / 20$ \\
\hline 26 & + & - & $20 / 20$ & $20 / 20$ & $20 / 20$ & $20 / 20$ & $20 / 20$ & $20 / 20$ \\
\hline 27 & + & - & $20 / 20$ & $20 / 20$ & $20 / 20$ & $20 / 20$ & $20 / 20$ & $20 / 20$ \\
\hline $28^{\mathrm{a}}$ & + & - & $20 / 60$ & $20 / 25$ & $20 / 60$ & $20 / 25$ & $20 / 60$ & $20 / 25$ \\
\hline 29 & + & - & $20 / 20$ & $20 / 20$ & $20 / 20$ & $20 / 20$ & $20 / 20$ & $20 / 20$ \\
\hline 30 & + & - & $20 / 20$ & $20 / 20$ & $20 / 20$ & $20 / 20$ & $20 / 20$ & $20 / 20$ \\
\hline 31 & + & - & $20 / 20$ & $20 / 20$ & $20 / 20$ & $20 / 20$ & $20 / 20$ & $20 / 20$ \\
\hline 32 & + & - & $20 / 20$ & $20 / 20$ & $20 / 20$ & $20 / 20$ & $20 / 20$ & $20 / 20$ \\
\hline 33 & + & - & $20 / 20$ & $20 / 20$ & $20 / 20$ & $20 / 20$ & $20 / 20$ & $20 / 20$ \\
\hline 34 & + & - & $20 / 20$ & $20 / 20$ & $20 / 20$ & $20 / 20$ & $20 / 20$ & $20 / 20$ \\
\hline 35 & + & + & $20 / 25$ & $20 / 20$ & $20 / 25$ & $20 / 20$ & $20 / 25$ & $20 / 20$ \\
\hline 36 & + & - & $20 / 20$ & $20 / 20$ & $20 / 20$ & $20 / 20$ & $20 / 20$ & $20 / 20$ \\
\hline 37 & - & - & $20 / 20$ & $20 / 20$ & $20 / 20$ & $20 / 20$ & $20 / 20$ & $20 / 20$ \\
\hline 38 & - & - & $20 / 20$ & $20 / 20$ & $20 / 20$ & $20 / 20$ & $20 / 20$ & $20 / 20$ \\
\hline 39 & - & - & $20 / 20$ & $20 / 20$ & $20 / 20$ & $20 / 20$ & $20 / 20$ & $20 / 20$ \\
\hline 40 & - & - & $20 / 20$ & $20 / 20$ & $20 / 20$ & $20 / 20$ & $20 / 20$ & $20 / 20$ \\
\hline 41 & - & - & $20 / 20$ & $20 / 20$ & $20 / 20$ & $20 / 20$ & $20 / 20$ & $20 / 20$ \\
\hline 42 & - & - & $20 / 20$ & $20 / 20$ & $20 / 20$ & $20 / 20$ & $20 / 20$ & $20 / 20$ \\
\hline 43 & - & - & $20 / 20$ & $20 / 20$ & $20 / 20$ & $20 / 20$ & $20 / 20$ & $20 / 25$ \\
\hline 44 & - & - & $20 / 20$ & $20 / 20$ & $20 / 20$ & $20 / 20$ & $20 / 20$ & $20 / 20$ \\
\hline 45 & - & - & $20 / 20$ & $20 / 20$ & $20 / 20$ & $20 / 20$ & $20 / 20$ & $20 / 20$ \\
\hline 46 & - & - & $20 / 20$ & $20 / 20$ & $20 / 20$ & $20 / 20$ & $20 / 20$ & $20 / 20$ \\
\hline 47 & - & - & $20 / 20$ & $20 / 20$ & $20 / 20$ & $20 / 20$ & $20 / 20$ & $20 / 20$ \\
\hline 48 & - & - & $20 / 20$ & $20 / 20$ & $20 / 20$ & $20 / 20$ & $20 / 20$ & $20 / 20$ \\
\hline
\end{tabular}

First VA, visual acuity at baseline; Second VA, visual acuity at the end of IFN therapy; Third VA, visual acuity at the end of the second year. ${ }^{\mathrm{a}} \mathrm{Myopic}$ degeneration.

pupillary defect was also present in this case. In 2 cases (nos. 13 and 22, Table 1) with chronic renal failure, cotton wool spots developed very close to the fovea resulting in a 1 or 2 line decrease in visual acuity. The IFN $\alpha$ dose was halved in the more severe case (no. 22) and the cotton wool spots disappeared in 4 weeks, with improvement of visual acuity. IFN $\alpha$ at standard dose was restarted. Until the end of therapy cotton wool spots were seen again outside the major vessels without any threat to the fovea.

One patient with chronic renal failure (no. 36, Table 1), complained of uniocular blurred vision with 20/20 acuity at the fifth week of therapy. Ophthalmoscopic examination revealed papilloedema with cotton wool spots and haemorrhages in the lower temporal quadrant (Fig. 2a). There were cotton wool spots in the other eye as well (Fig. 2b). Two days later the visual acuity was counting fingers from $3 \mathrm{~m}$ and a full-blown picture of hemispheric retinal vein occlusion was observed (Fig. 2c). Blood pressure was within normal limits. IFN $\alpha$ therapy was interrupted. Within 2 weeks neovascularisation developed at the disc, which responded to photocoagulation therapy. After 6 weeks IFN $\alpha$ therapy was restarted. Nine months later, at the end of 1 year of therapy, visual acuity was 20/20 with an upper quadrant visual field defect (Fig. 2d). 


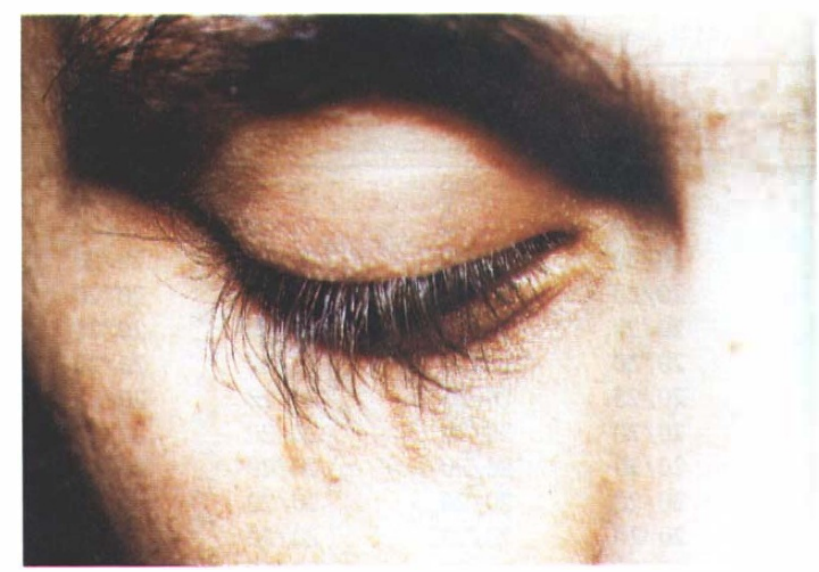

Fig. 1 Trichomegaly in case no. 10.

Of 19 cases with chronic renal failure, 9 developed interferon-associated retinopathy (Table 1). This was not significant statistically $(p>0.05)$. However, in 2 cases, IFN $\alpha$ therapy had to be modified.

In all cases, blood pressure and blood glucose levels were within normal limits at all examinations.

Leucopenia was noted in 5 patients, of whom 2 had retinopathy and 1 had preseptal cellulitis. Haematocrit values were less than normal (41-54\% for males, $37-47 \%$ for females) in 19 patients, of whom 8 had retinopathy. Platelet levels were less than $140000 / \mathrm{mm}^{3}$ in 12 patients,

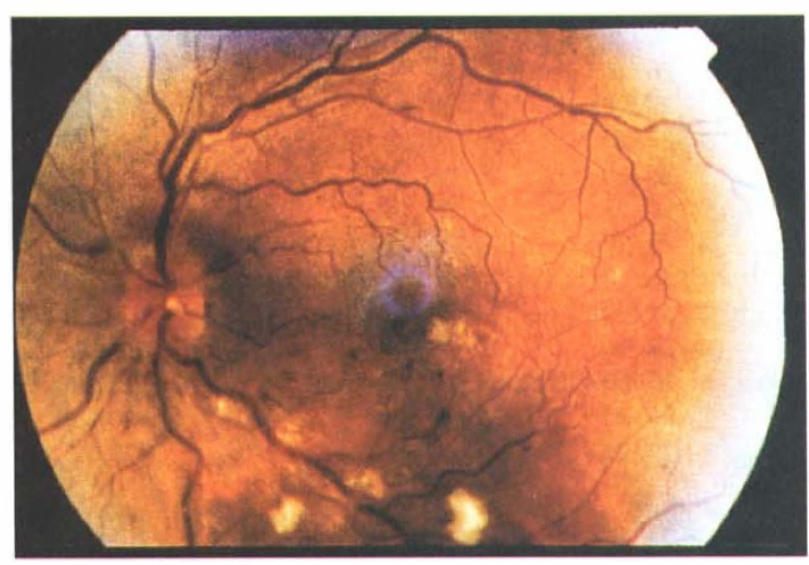

(a)

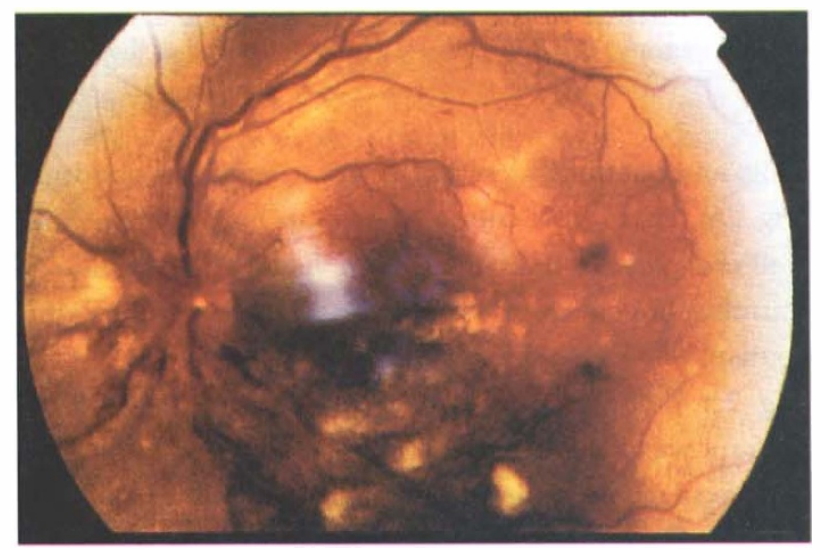

(c) of whom 5 had retinopathy (Table 1). Decreased haematocrit and platelet counts in patients with retinopathy were not statistically significant $(p>0.05$, $p>0.05$, respectively).

Ophthalmoscopic examinations in the year after the end of IFN $\alpha$ therapy revealed no new haemorrhages or cotton wool spots.

In the group without IFN $\alpha$ therapy no retinopathy was detected during 2 years of follow-up.

\section{Discussion}

Recombinant IFN $\alpha$ has been employed as therapy for chronic hepatitis. ${ }^{1,2,6,7}$ Treatment has been accompanied by various side-effects. ${ }^{3,4}$ Some ocular complications were thought to be coincidental as they were extremely rare. ${ }^{5}$ These include one case of oculomotor nerve paralysis, two cases of hypertrichosis, ${ }^{8}$ one case of induction of acute corneal allograft rejection ${ }^{9}$ and one case of papilloedema. ${ }^{5}$

We report 2 additional cases in which the cilia became prominent due to the increase in length and thickness after 6 months of IFN $\alpha 10 \mathrm{MIU}$, three times weekly. The previous reported cases had been receiving $50 \mathrm{MIU}$ IFN $\alpha$

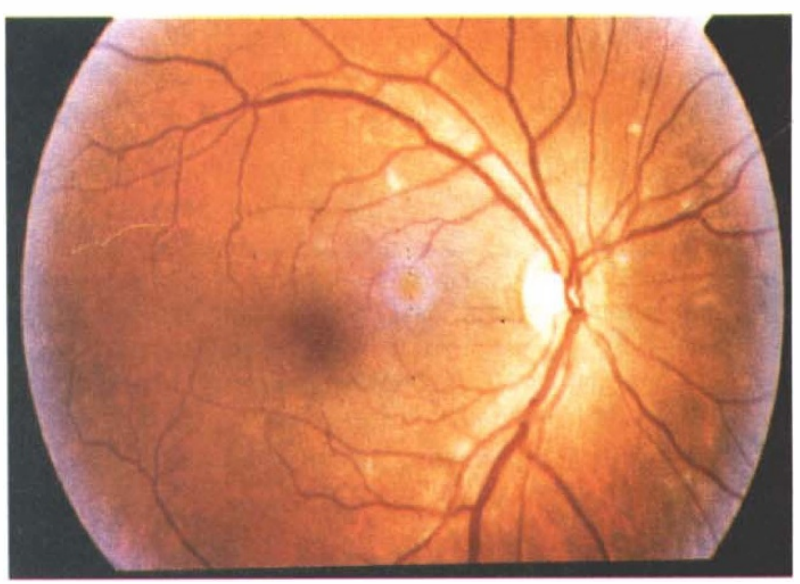

(b)

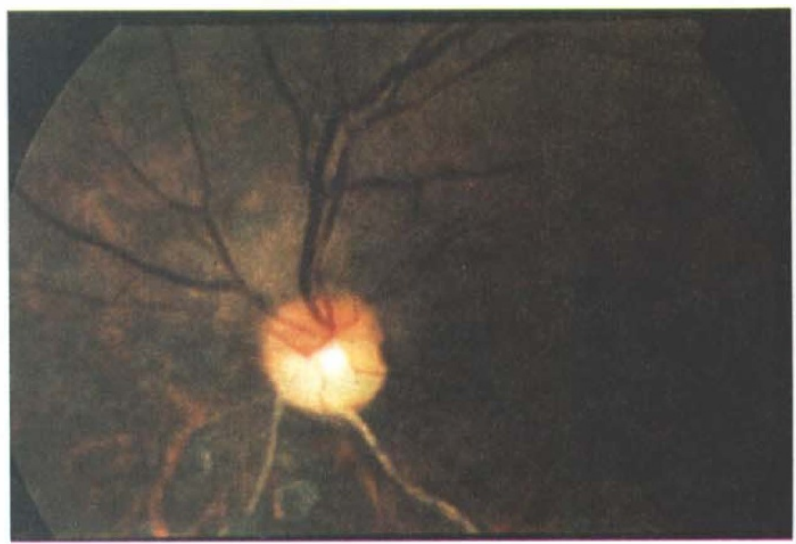

(d)

Fig. 2. Case no. 36. (a) Papilloedema with cotton wool spots and haemorrhages, left eye. (b) Cotton wool spots, right eye. (c) Hemispheric retinal vein occlusion, left eye. (d) Left eye, 1 year later. 
per square metre of body surface area, intramuscularly three times weekly. ${ }^{8}$ The mechanism causing the changes in the cilia is unknown.

With extended use of IFN $\alpha$, especially in high doses, reports of retinopathy have been increasing. ${ }^{5-7,10-12}$ In various series, the incidence of retinopathy in cases undergoing IFN $\alpha$ therapy has been between $11.1 \%$ and $86 \%{ }^{7,10-12}$ In our series, $42 \%$ developed retinopathy.

Retinal changes were noted early in the course of IFN $\alpha$ therapy, as in other studies.,10-12

Retinopathy associated with chronic hepatitis has also been reported without IFN $\alpha$ therapy, with mild thrombocytopenia, long-term hepatitis illness, advanced age, liver cirrhosis and a history of systemic hypertension being the major risk factors. ${ }^{13}$ In this study we did not observe any retinopathy either in the control group or in the IFN $\alpha$ group after the cessation of therapy.

The pathogenesis of interferon-associated retinopathy is unclear. Cotton wool spots are the result of the obstruction of axoplasmic flow secondary to ischaemia of the retinal vasculature. It is speculated that IFN $\alpha$ therapy may cause deposition of immune complexes in the retinal vasculature; leucocyte infiltration with subsequent retinal ischaemia could then lead to capillary non-perfusion and cotton wool spot formation. ${ }^{5}$ It has also been suggested that complement activation occurs in patients treated with IFN $\alpha$ and that activation of complement 5a can lead to retinal capillary infarction and retinal hemorrhage. ${ }^{6}$ Another study indicated that red blood cell count decreased significantly in patients with retinopathy compared with those without retinopathy. ${ }^{10}$ In our cases there was no significant difference between the haematocrit values of patients with or without retinopathy. Hararda et al. ${ }^{11}$ reported cotton wool spots combined with splinter haemorrhages in 4 patients and stated that interferons could not be primarily responsible for the development of retinopathy as, in 2 patients, cotton wool spots and haemorrhages disappeared irrespective of continued IFN therapy. However, IFN $\alpha$-induced leucocyte adherence to the vascular endothelium and subsequent leucocyte trapping in the retinal capillaries, which was dose-dependent, has recently been shown in rats. ${ }^{14}$

In most of our cases, retinopathy resolved despite continued therapy. We, under the guidance of previous reports, also elected to follow the patients without modifying the therapy, except for 2 cases. In the patient with hemicentral retinal vein occlusion, the treatment was interrupted for 6 weeks. In one patient with macular involvement and a 2 line decrease in visual acuity, the dose was halved.

IFN $\alpha$ has also been tried in the treatment of agerelated macular degeneration and ocular complications have also been reported in some of these series. ${ }^{5,15-17}$ No ocular side-effect was reported in patients receiving short-term IFN $\alpha$ therapy of $3 \mathrm{MIU}$, three times weekly, for ocular Behçet's disease. ${ }^{18}$ This suggests a possible role of higher dosage in the occurrence of retinopathy. In rats, it has been shown that leucocyte trapping in the microcirculation is dose-dependent. ${ }^{14}$ We do not think that the duration of the treatment is important since retinal changes are seen early in the course of the therapy. In 121 patients with age-related macular degeneration taking 6 MIU IFN $\alpha$ three times weekly, retinopathy has been reported in only $5 \% .{ }^{17}$ The disparity between this finding and our results may be because in that study patients with significant hepatic and/or renal disease had been excluded, while our patient group was composed of chronic hepatitis patients some of whom also had renal failure. Renal and hepatic disease may exacerbate the retinal toxic effect of IFN $\alpha$.

Retinal vein occlusion has not been reported in association with IFN $\alpha$ therapy. Our case (no. 36) may not be directly related to IFN $\alpha$. The patient was 39 years old, had chronic renal failure and, although her blood pressure seemed to be under control, we cannot rule out other factors for vein occlusion; however, we suspect that IFN $\alpha$ had an additive effect.

In previous reports it has been stated that IFN $\alpha$ associated retinopathy was more common among diabetic or hypertensive patients. ${ }^{12}$ In our series chronic renal failure was the major systemic problem. We did not find a statistically significant association between IFNassociated retinopathy and chronic renal failure.

However, we observed that retinopathy was more severe in patients with chronic renal failure, requiring modification of the therapy.

No treatment appears indicated in most cases since the lesions appear to resolve spontaneously. However, experimental studies suggest that some antiinflammatory drugs that modulate leucocyte-endothelial interactions would be effective in the inhibition of leucocyte entrapment in the microcirculation. ${ }^{19}$ These could be considered in progressive cases or when visual acuity is compromised.

In conclusion, patients receiving IFN $\alpha$, especially those with accompanying systemic disease, should be monitored for ocular side-effects. The use of protective agents for the microcirculation may need to be considered.

\section{References}

1. Baron S, Tyring SK, Fleischmann WR Jr, Coppenhaver DH, Niesel DW, Klimpel GR, et al. The interferons: mechanisms of action and clinical applications. JAMA 1991;226:1375-83.

2. Perrillo RP. Treatment of chronic hepatitis B with interferon: experience in western countries. Semin Liv Dis 1989;9:240-8.

3. Product information sheet. Kenilworth, NJ: Schering Corporation, 1988.

4. Jones GJ, Itri L. Safety and tolerance of recombinant interferon alpha-2a (Roferon-A) in cancer patients. Cancer 1986;57:1709-15.

5. Guyer DR, Tiedeman J, Yannuzzi LA, Slakter JS, Parke D, Kelley J, et al. Interferon-associated retinopathy. Arch Ophthalmol 1993;111:350-6.

6. Sugano S, Yanagimoto M, Suzuki T, Sato M, Onmura H, Aizawa H, Makino H. Retinal complications with elevated circulating plasma $\mathrm{C} 5 \mathrm{a}$ associated with interferon- $\alpha$ therapy for chronic active hepatitis C. Am J Gastroenterol 1994;89:2054-6. 
7. Soushi S, Kobayashi F, Obazawa H, Kigasawa K, Shiraishi K, Itakura $\mathrm{M}$, et al. Evaluation of risk factors of interferonassociated retinopathy in patients with type $C$ chronic active hepatitis. Nippon Ganka Gakkai Zasshi 1996;100:69-76.

8. Foon KA, Dougher G. Increased growth of eyelashes in a patient given leukocyte A interferon. $\mathrm{N}$ Engl J Med 1984;311:1259.

9. Jacobs AD, Levenson JE, Goldie DW. Induction of acute corneal allograft rejection by alpha-2 interferon. Am J Med 1987;82:181-2.

10. Chuman T, Nao-i N, Sawada A, Kawano T, Shigehira M. Interferon-induced retinal changes. Nippon Ganka Gakkai Zasshi 1994;98:616-21.

11. Hararda T, Fukami H, Takeuchi T, Niwa T, Majima Y. Interferone-assozierte Retinopathie. Klin Monatsbl Augenheilkd 1995;207:302-4.

12. Kawano T, Shigehira M, Uto H, Nakama T, Kato J, Hayashi $\mathrm{K}$, et al. Retinal complications during interferon therapy for chronic hepatitis C. Am J Gastroenterol 1996;91:309-13.

13. Ab T, Nakajima A, Satoh N, Koizumi T, Sakuragi S, Ono T, et al. Clinical characteristics of hepatitis $C$ virus-associated retinopathy. Jpn J Ophthalmol 1995;39:411-9.
14. Nishiwaki H, Ogura Y, Miyamoto K, Matsuda N, Honda Y. Interferon alpha induces leukocyte capillary trapping in rat retinal microcirculation. Arch Ophthalmol 1996;114:726-30.

15. Engler C, Sander B, Villumsen J, Lund Andersen H. Interferon alpha-2a modifies the course of subfoveal and juxtafoveal choroidal neovascularisation. $\mathrm{Br} \mathrm{J}$ Ophthalmol 1994;78:749-53.

16. Chan CK, Kempin SJ, Noble SK, Palmer GA. The treatment of choroidal neovascular membranes by alpha interferon: an efficacy and toxicity study. Ophthalmology 1994;101:289-300.

17. Pharmacological Therapy for Macular Degeneration Study Group. Interferon alpha-2a is ineffective for patients with choroidal neovascularisation secondary to age related macular degeneration. Arch Ophthalmol 1997;115:865-72.

18. Çalişkan S, Eldem B, Demiroğlu H, Yaylali V, Ozcebe OI, Dündar S. Interferon alpha-2b in the treatment of Behçet's disease. Middle East J Ophthalmol 1995;3:94-9.

19. Nishiwaki H, Ogura Y, Miyamoto K, Hiroshiba N, Hamada M, Honda Y. Prednisolone, platelet-activating factor receptor antagonist, or superoxide dismutase reduced leukocyte entrapment induced by interferon alpha in retinal microcirculation. Invest Ophthalmol Vis Sci 1997;38:811-6. 